\title{
Potent and Selective Bruton's Tyrosine Kinase Inhibitors: Discovery of GDC-0834
}

\author{
Wendy B. Young* a , James Barbosa ${ }^{\text {b }}$, Peter Blomgren ${ }^{\mathrm{b}}$, Meire C. Bremer ${ }^{\mathrm{a}}$, James J. Crawford ${ }^{\mathrm{a}}$, Donna \\ Dambach $^{\mathrm{a}}$, Steve Gallion ${ }^{\mathrm{c}}$, Sarah Hymowitz ${ }^{\mathrm{a}}$, Jeffrey E. Kropf ${ }^{\mathrm{b}}$, Seung H. Lee ${ }^{\mathrm{b}}$, Lichuan Liu ${ }^{\mathrm{a}}$, Joe \\ Lubach $^{\mathrm{a}}$, Jen Macaluso ${ }^{\mathrm{b}}$, Pat Maciejewski ${ }^{\mathrm{b}}$, Brigitte Maurer ${ }^{\mathrm{a}}$, Scott A. Mitchell ${ }^{\mathrm{b}}$, Daniel F. Ortwine ${ }^{\mathrm{a}}$, \\ Julie Di Paolo ${ }^{\mathrm{b}}$, Karin Reif ${ }^{\mathrm{a}}$, Heleen Scheerens ${ }^{\mathrm{a}}$, Aaron Schmitt ${ }^{\mathrm{b}}$, C. Gregory Sowell ${ }^{\mathrm{a}}$, Xiaojing Wang ${ }^{\mathrm{a}}$, \\ Harvey Wong ${ }^{\mathrm{a}}$, Jin-Ming Xiong ${ }^{\mathrm{b}}$, Jianjun $\mathrm{Xu}^{\mathrm{b}}$, Zhongdong Zhao ${ }^{\mathrm{b}}$ and Kevin S. Currie ${ }^{\mathrm{b}}$
}

${ }^{a}$ Genentech, 1 DNA Way, South San Francisco, CA 94080

${ }^{b}$ Gilead Sciences, 36 East Industrial Rd., Branford, CT 06405 (formerly CGI Pharmaceuticals)

${ }^{c}$ St. Andrews Circle, Wallingford, CT 06492

\section{ARTICLE INFO}

\section{Article history:}

Received

Revised

Accepted

Available online

Keywords:

Kinase inhibitor, Bruton's tyrosine kinase, Btk, Rheumatoid arthritis, GDC-0834, Amide hydrolysis, single dose IND

\section{ABSTRACT}

SAR studies focused on improving the pharmacokinetic (PK) properties of the previously reported potent and selective Btk inhibitor CGI-1746 (1) resulted in the clinical candidate GDC0834 (2), which retained the potency and selectivity of CGI-1746, but with much improved PK in preclinical animal models. Structure based design efforts drove this work as modifications to 1 were investigated at both the solvent exposed region as well as "H3 binding pocket." However, in vitro metabolic evaluation of $\mathbf{2}$ revealed a non CYP-mediated metabolic process that was more prevalent in human than preclinical species (mouse, rat, dog, cyno), leading to a high-level of uncertainly in predicting human pharmacokinetics. Due to its promising potency, selectivity, and preclincial efficacy, a single dose IND was filed and $\mathbf{2}$ was taken in to a single dose phase I trial in healthy volunteers to quickly evaluate the human pharmacokinetics. In human, 2 was found to be highly labile at the exo-cyclic amide bond that links the tetrahydrobenzothiophene moiety to the central aniline ring, resulting in insufficient parent drug exposure. This information informed the back-up program and discovery of improved inhibitors.

2009 Elsevier Ltd. All rights reserved.

Bruton's tyrosine kinase (Btk) plays a critical role in the development, differentiation and proliferation of B-lineage cells, making it an attractive target for the treatment of immunological disorders such as (rheumatoid arthritis (RA), lupus, multiple sclerosis (MS) $)^{1-4}$ as well as B-cell malignancies. ${ }^{5}$ It has been reported that 1 in 150,000 males is born with a deficiency in the Btk gene, ${ }^{6}$ a condition called X-linked agammaglobulinemia (XLA), manifested by lack of immunoglobulins and B cells and first reported by Ogden Bruton in 1952. ${ }^{7-8}$ A related but less severe X-linked immunodeficiency (xid) in mice is also known. ${ }^{9-}$ ${ }_{10}$ Importantly, these $x i d$ mice are resistant to acquiring lupus ${ }^{11}$ and collagen induced arthritis. ${ }^{12}$ In addition to B cells, Btk also plays an important role in myeloid cell inflammatory cytokine production. ${ }^{2-4}$ Thus, there have been significant efforts from the pharmaceutical community with the goal of identifying Btk inhibitors for clinical development. ${ }^{13-16}$ Of these, the most advanced compound in oncology indications is ibrutinib/Imbruvica ${ }^{\circledR},{ }^{17-18}$ which was recently approved for the treatment of mantle cell lymphoma (MCL) and chronic lymphocytic leukemia (CLL) ${ }^{19}$ and remains under evaluation in additional indications. ${ }^{20}$ The most advanced Btk inhibitor in nononcology indications is CC- 292, which is currently in Phase IIa studies in RA patients. ${ }^{21}$

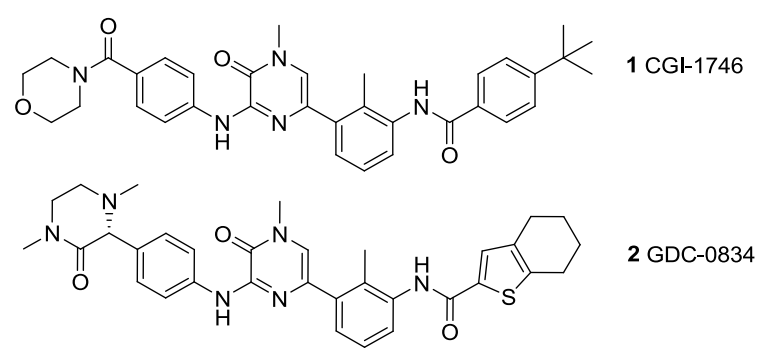

Figure 1 Btk inhibitors CGI-1746 (1) and GDC-0834 (2) 
We previously reported on the discovery of CGI-1746 (1), ${ }^{3,22-}$ 23 a potent, highly selective, non-covalent, reversible inhibitor of Btk and an ideal tool molecule to investigate the biological role that Btk signaling plays in rheumatoid arthritis and other B cell and immune complex-mediated disorders. CGI-1746 (1) was shown to be efficacious in several animal models of rheumatoid arthritis. ${ }^{3}$ Although 1 was not considered to be a viable drug candidate based on its poor ADME properties, it was an appealing scaffold by virtue of its exquisite selectivity profile, due to an induced 'H3' specificity pocket. For this reason, we chose to pursue further development of this scaffold. In this report, we describe the optimization of $\mathbf{1}$ to molecules with improved drug-like properties, culminating in our first Btk inhibitor clinical candidate, GDC-0834, 2.

As reported by Di Paolo, et. al. $^{3}$ the CGI-1746 (1) scaffold binds in an extended conformation to Btk as illustrated in Figure 2. This binding event induces a conformational change in Btk relative to the Apo structure (pdb 3P08) resulting in a Src-like inactive conformation of the kinase domain. This includes rearrangement of Y551 by $\sim 18 \AA$ from an extended, solvent exposed position to a buried conformation. The t-butyl phenyl group of CGI-1746 (1) binds into a lipophilic pocket (termed the $\mathrm{H} 3$ pocket). The pyrazinone $\mathrm{HN}-\mathrm{C}-\mathrm{C}-\mathrm{CO}$ binds to the hinge M477 while the morpholine-amide extends into solvent.

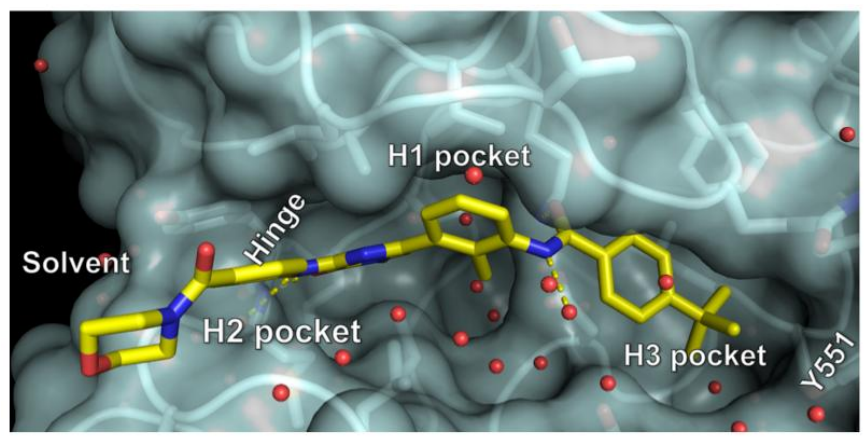

Figure 2 X-ray crystal structure of CG1-1746 (1) bound in Btk (pdb code $3 \mathrm{OCS}^{3}$ ) illustrating the location of key regions of Btk and important interactions with CGI-1746.

Our initial SAR studies evaluated the effect of varying the substitution on the terminal phenyl ring of $\mathbf{1}$ as well as replacing this ring with alternate arenes on binding interactions in the $\mathrm{H} 3$ pocket. Over 100 analogs were synthesized with representative examples shown in Table 1. We assessed inhibition against the target enzyme (Btk) as well as the downstream effect on antiIgM-stimulated cell surface CD86 expression. Since the binding pocket is relatively confined and comprised of a series of lipophilic residues, only a small subset of these analogs bound well. For instance, the unsubstituted phenyl $\mathbf{3}$ had poor binding affinity with an $\mathrm{IC}_{50}$ of $4.6 \mathrm{uM}$ but addition of para subsitutents, as in $\mathbf{1}$ and 4-11, all offered increased potency as compared to 3 . The thiophene isostere, 12, was fairly potent but still inferior to $\mathbf{1}$. Indeed, the original lead CGI-1746 (1), possessing a para-t-butyl group, was the best from this initial series. Unfortunately, this compound suffered from poor pharmacokinetic properties in rat (clearance $(\mathrm{CL})=87 \mathrm{~mL} / \mathrm{min} / \mathrm{kg}$; oral bioavailability $(\mathrm{F} \%)$ $<5 \%$ ), so an early goal was to improve the oral exposure of this compound. Adding polarity to the aryl ring, as in examples 13$\mathbf{1 6}$, caused a decrease in binding affinity in all cases, presumably due to clashes with lipophilic residues in the binding pocket. We were able to identify tetrahydrobenzothiophene 17 that did maintain equivalent potency to $\mathbf{1}$, although related analogs $\mathbf{1 8 - 2 1}$ failed to offer any improvement in affinity. Importantly, from this set, 17, represented the only example with improved clearance and appreciable oral bioavailability in rat $(\mathrm{CL}=6.0$ $\mathrm{mL} / \mathrm{min} / \mathrm{kg} ; \mathrm{F}=29 \%$ ). At this point, we sought to optimize the other parts of the molecule while maintaining the tetrahydrobenzothiophene moiety in the $\mathrm{H} 3$ pocket. Thiophenes can be problematic from a medicinal chemistry viewpoint given that they are known to undergo bioactivation to yield reactive metabolites, ${ }^{25-26}$ despite there being examples of marketed, oral and chronically dosed drugs featuring this motif. ${ }^{27}$ In this case, we reasoned that the risk was mitigated given the steric bulk (trisubstituted thiophene) and electron withdrawing effect of the adjacent acyl group.

Table 1. Btk activity SAR for $\mathrm{H} 3$ group variations.

\begin{tabular}{|c|c|c|c|}
\hline \multirow{2}{*}{ Compound ID } & \multirow{2}{*}{$\mathbf{R}$} & \multicolumn{2}{|c|}{$\mathrm{IC}_{50}(\mathrm{uM})^{\mathrm{a}}$} \\
\hline & & Btk ${ }^{\mathbf{a}}$ & CD86 $^{\mathrm{a}}$ \\
\hline 3 & & 4.60 & -- \\
\hline 4 & $-\{--$ & 0.86 & -- \\
\hline 5 & & 0.225 & -- \\
\hline CGI-1746 (1) & & 0.008 & 0.15 \\
\hline 6 & & 0.23 & 0.41 \\
\hline 7 & & 0.04 & 0.08 \\
\hline 8 & & 0.11 & -- \\
\hline 9 & & 0.03 & 0.58 \\
\hline 10 & $-\{-1$ & 0.15 & 2.8 \\
\hline 11 & & 0.09 & 1.1 \\
\hline 12 & & 0.06 & 0.49 \\
\hline 13 & $-\xi-1$ & 0.27 & 3.7 \\
\hline 14 & & 0.05 & -- \\
\hline 15 & & 0.13 & 3.5 \\
\hline 16 & & 0.07 & 0.89 \\
\hline 17 & & 0.008 & 0.23 \\
\hline 18 & & 0.15 & 1.3 \\
\hline 19 & & 0.34 & -- \\
\hline 20 & & 0.19 & -- \\
\hline 21 & & 0.03 & -- \\
\hline
\end{tabular}

a) assay conditions in supplementary materials 
Table 2 SAR for $\mathrm{H} 2$ group variations

\begin{tabular}{|c|c|c|c|c|}
\hline \multirow{2}{*}{$\begin{array}{c}\text { Compound } \\
\text { ID }\end{array}$} & \multirow{2}{*}{$\mathbf{R}$} & \multicolumn{2}{|c|}{$\mathrm{IC}_{50} \mathrm{uM}$} & \multirow{2}{*}{$\begin{array}{l}\text { Rat } \\
\mathbf{C L}^{\mathrm{a}} / \mathbf{F}^{\mathrm{b}}\end{array}$} \\
\hline & & Btk & CD86 & \\
\hline 17 & & 0.008 & 0.23 & $6.0 / 29 \%$ \\
\hline 22 & & 0.23 & -- & -- \\
\hline 23 & & 0.050 & 5.0 & $9.2 / 53 \%$ \\
\hline 24 & & 0.49 & -- & -- \\
\hline 25 & & 0.65 & -- & $5.4 / 37 \%$ \\
\hline 26 & & 0.043 & 1.1 & -- \\
\hline 27 & & 0.21 & -- & -- \\
\hline 28 & & 0.054 & 1.3 & -- \\
\hline 29 & & 0.01 & 0.06 & $\begin{array}{c}111 /< \\
5 \%\end{array}$ \\
\hline 30 & & 0.06 & 0.80 & -- \\
\hline 31 & & 0.05 & 23.9 & -- \\
\hline 32 & & 0.02 & 0.16 & $11 / 41 \%$ \\
\hline 2 & & 0.006 & 0.06 & $4.4 / 35 \%$ \\
\hline
\end{tabular}

Our next efforts focused on determining the scope of moieties that would be tolerated in the partially solvent-exposed $\mathrm{H} 2$ region. Over 300 compounds were prepared in this endeavor, with a range of these shown in Table 2 . Inhibitors with unsubstituted mono aryl groups 22-25 lost significant potency. Bicyclic analogs such as 26-28 likewise failed to match the enzyme potency of CGI-1746 (1). Ultimately, extending moieties from the para position of the aryl ring appeared to offer the best balance of biochemical and cellular potency while retaining acceptable pharmacokinetic properties in rat. $\mathrm{N}$-Mepiperidine-containing example 29 proved to be highly potent but suffered from high in vivo $\mathrm{CL}$ in rat $(111 \mathrm{~mL} / \mathrm{min} / \mathrm{kg})$. Lower in vivo $\mathrm{CL}$ was found with the dimethyl-3-oxopiperazin-2-yl enantiomers, 32 and 2. The absolute configuration of $\mathbf{2}$ was determined by a single crystal X-ray. Accordingly, $\mathbf{3 2}$ was then assigned as the opposite enantiomer. Between $\mathbf{2}$ and 32, a 3 -fold potency difference was observed between the enantiomers in vitro, and thus compound $\mathbf{2}$ was selected for further studies and ultimately was nominated as the clinical candidate, GDC-0834 (2).

GDC-0834 (2) inhibits Btk in vitro with an $\mathrm{IC}_{50}$ of $0.006 \mathrm{uM}$ and has an EC50 of $0.060 \mathrm{uM}$ in the cell based CD86 assay. In human whole blood, 2 demonstrated potent inhibition of both anti-IgE stimulated CD63 expression (basophils) and anti-IgD stimulated CD69 expression (B-cells) with EC50's of 0.35 and $0.38 \mathrm{uM}$, respectively (Table 3). Additionally, GDC-0834 (2) has shown efficacy in a rat collagen-induced arthritis (CIA) model, causing a dose-dependent decrease of ankle swelling and reduction of morphologic pathology. ${ }^{28}$

Table 3 Human Potency of GDC-0834 (2)

\begin{tabular}{|c|c|c|c|}
\hline $\begin{array}{c}\text { Enzyme } \\
\text { IC }_{50}\end{array}$ & $\begin{array}{c}\text { B-cell } \\
\text { EC }_{50}\end{array}$ & \multicolumn{2}{|c|}{$\begin{array}{c}\text { whole blood } \\
\text { EC }_{50}\end{array}$} \\
\hline \multirow{2}{*}{ Btk } & \multirow{2}{*}{ CD86 } & basophils & B-cell \\
\cline { 3 - 4 } & & CD63 & CD69 \\
\hline $0.006 \mathrm{uM}$ & $0.06 \mathrm{uM}$ & $0.35 \mathrm{uM}$ & $0.38 \mathrm{uM}$ \\
\hline
\end{tabular}

Importantly, GDC-0834 (2) retained the same selectivity profile as CG1-1746 (1) demonstrating excellent biochemical selectivity against a panel of 331 kinases (Figure 3 ). The sole exception was the TEC-family kinase $\mathrm{Bmx}^{29}$ for which there was only a 3-fold preference for Btk based on biochemical $\mathrm{IC}_{50}$ values. Additionally, GDC-0834 (2) had minimal to no off-target receptor activity when screened against a panel of 30 targets (all $<35 \%$ at $10 \mathrm{uM})$, minimal inhibition of the hERG channel $(27 \%$ at $10 \mathrm{uM}$ ), and was negative in a gene-tox profile Ames (TA98/100 strains; +/- S9) and micronucleus tests (+/- S9).

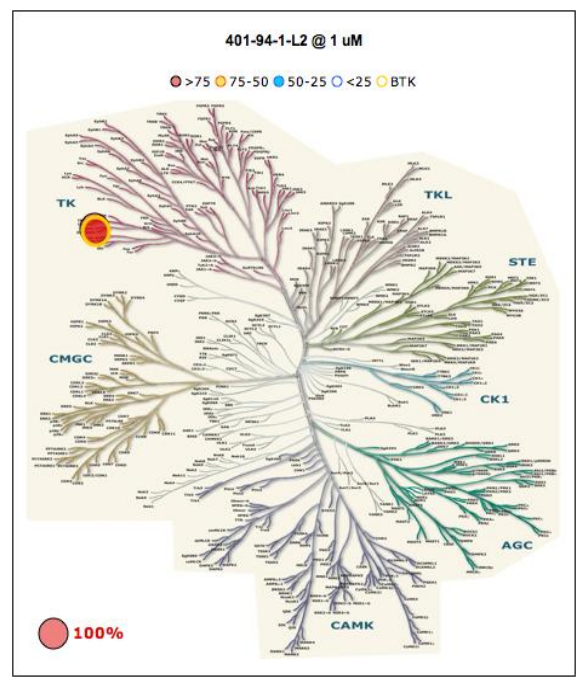

Figure 3 Kinase selectivity profile of GDC-0834 (2) vs. a panel of 331 kinases at $1 \mathrm{uM}$ concentration.

We obtained a $1.95 \AA$ resolution crystal structure of GDC0834 (2) in complex with Btk, ${ }^{30}$ confirming a near-identical binding configuration to CGI-1746 (Figure 4). The conformation of the Btk kinase domain is also very similar between the two structures with an r.m.s.d. of $0.12 \AA 2$ over 1838 atoms. The tetrahydrobenzothiophene moiety binds in the $\mathrm{H} 3$ pocket created by residues L542, V546, S543, and Y551 of the fully ordered activation loop. The side chains of the Gly-rich loop residues Q412 and F413, the backbone of residues T410 and 
G411, as well as the catalytic loop residues D521 and N526, and the DFG residue D539 also contribute to the specificity. The amide linking the central aryl to the tetrahydrobenzothiophene makes interactions identical to those observed in the CGI-1746Btk co-crystal structure, including a non-classical hydrogen bond to $\mathrm{K} 430$. The pyrazinone $\mathrm{HN}-\mathrm{C}-\mathrm{C}-\mathrm{CO}$ binds to the hinge M477 while the dimethyl-3-oxopiperazin-2-yl extends into the solvent region where it can likely access more than one conformation.
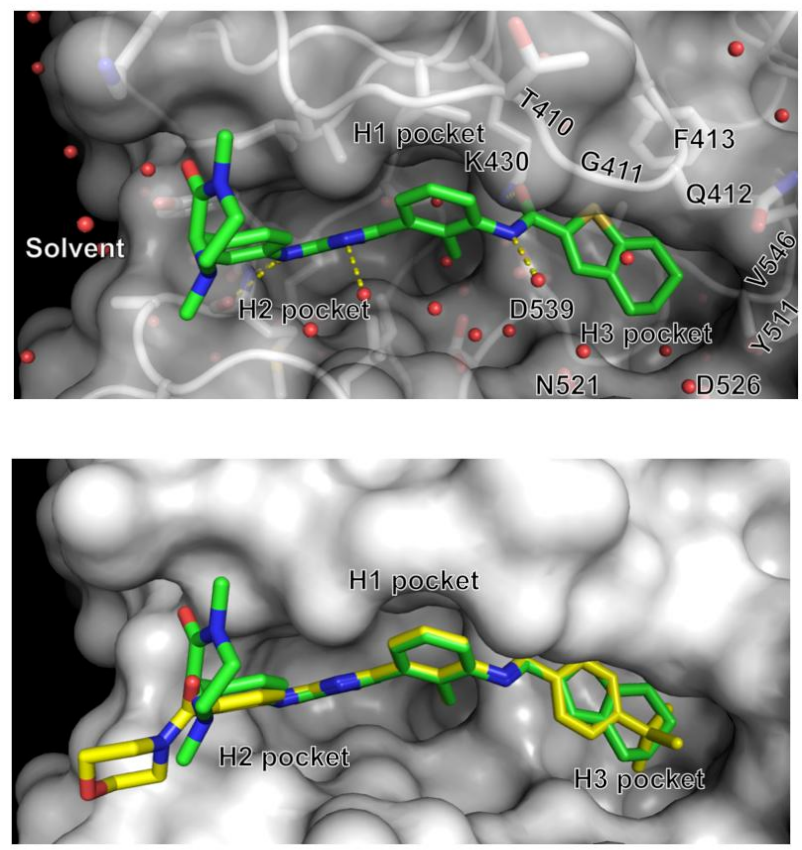

Figure 4: a) Crystal structure of GDC-0834 (2) in Btk; b) Comparison of the binding modes of CGI-1746 and GDC-0834.

Scheme 1: Synthesis of GDC-0834

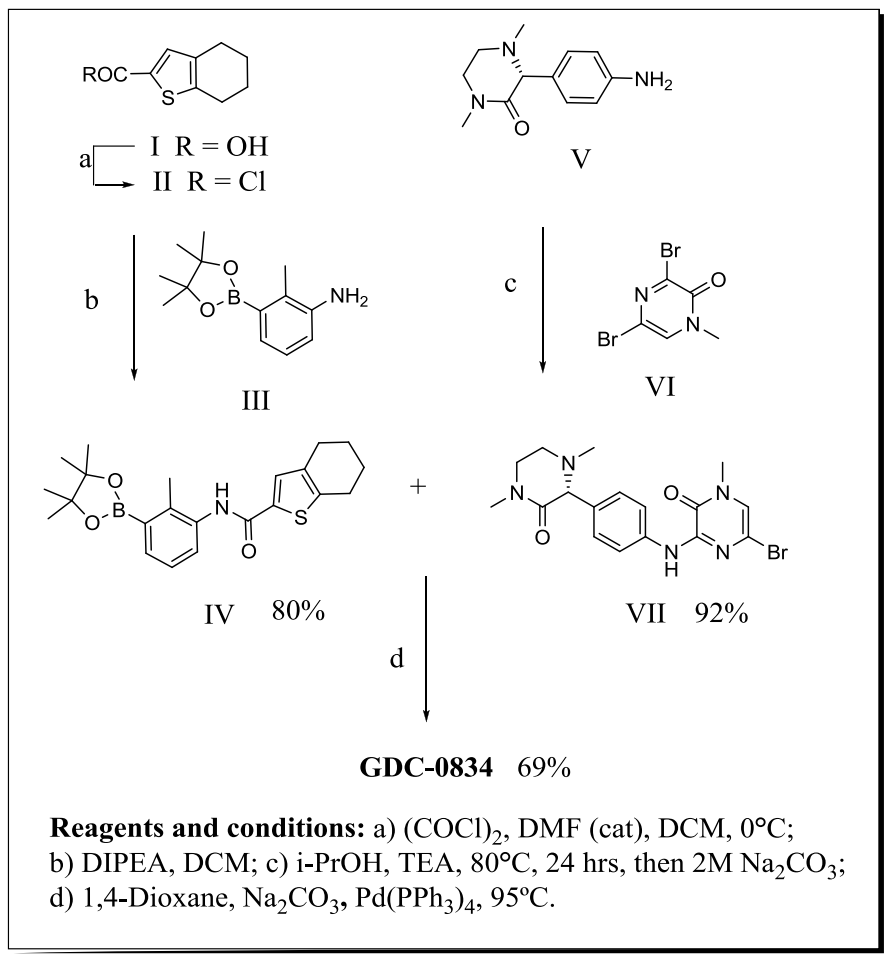

The original synthesis of GDC-0834 (2) has been previously reported. ${ }^{31}$ Here, in Scheme 1 (with full details in Supplemental Material), we outline an improved method for larger scale production. Carboxylic acid I was transformed to the acid chloride II via the action of oxalyl chloride in DCM. Thereafter, reaction of acid chloride II with amino-boronate III afforded IV in $80 \%$ yield from $\mathbf{I}$. Aniline $\mathbf{V}$ (single stereoisomer) underwent coupling with dibromopyrazinone VI to afford VII. Final coupling of bromo-pyrazine VII and boronate IV catalyzed by tetrakis(triphenylphosphine)palladium provided GDC-0834 (2).

GDC-0834 (2) exhibited low clearance in rats, moderate clearance in mice and dogs, and high clearance in cynomologus monkeys (Table 4). Oral bioavailability was acceptable in all species and showed that oral exposures were achievable following crystalline suspension. The rat oral bioavailability of crystalline freebase suspension was slightly lower compared to solution, presumably due to low solubility limiting its oral absorption $\left(\mathrm{mp}=212{ }^{\circ} \mathrm{C}\right.$; solubility $=0.007 \mathrm{mg} / \mathrm{mL}$ in fastedstate simulated intestinal fluid $\mathrm{pH} 6.8,37^{\circ} \mathrm{C}$ ). However, data from dogs, suggested otherwise since oral bioavailablity was similar when comparing solution and crystalline freebase suspension dosing.

In vitro studies in liver microsomes and hepatocytes were run with GDC-0834 (2) in order to aid in an estimation of human clearance. Of note, the in vitro to in vivo correlation was variable among the preclinical species, and was particularly poor in the rat which suggested a large overestimation of in vivo clearance by in vitro methodologies (Table 4). In vitro liver microsome studies were run in the presence and absence of NADPH in order to characterize the extent of non cyp-mediated metabolism that had not previously been observed. The in vitro clearance of $\mathbf{2}$ in the absence of NADPH was identical to that measured in the presence of NADPH in human microsomes, suggesting significant non cyp-mediated metabolism. Non CYP-mediated metabolism was less pronounced in other species (mouse, rat, $\mathrm{dog}$, and cyno). As previously reported ${ }^{24}$, the clearance of GDC-0834 (2) in human was predicted to be low to moderate when projected from preclinical species using allometric scaling of in vivo data, but high from human microsomes and hepatocytes $\left(\mathrm{CL}_{\text {hep }} 19,19 \mathrm{~mL} / \mathrm{min} / \mathrm{kg}\right.$, respectively). Overall, the predicted human clearance ranged from low to high.

Table 4 GDC-0834 Preclinical Data

\begin{tabular}{|c|c|c|c|c|}
\hline \multicolumn{5}{|c|}{ Preclinical DMPK Data } \\
\hline \multirow[b]{3}{*}{ species } & \multicolumn{3}{|c|}{ Clearance $\mathrm{mL} / \mathrm{min} / \mathrm{kg}$} & \multirow{3}{*}{$\begin{array}{c}\text { Oral } \\
\text { Bioavailability } \\
\text { sol. }^{\text {a }} \text { (susp.) }\end{array}$} \\
\hline & \multicolumn{2}{|c|}{ in vitro } & \multirow[b]{2}{*}{$\begin{array}{c}\text { in } \\
\text { vivo }\end{array}$} & \\
\hline & $\begin{array}{c}\text { Liver } \\
\text { microsomes } \\
\text { (+/-NADPH) }\end{array}$ & $\begin{array}{c}\text { Liver } \\
\text { hepatocytes }\end{array}$ & & \\
\hline human & $19 / 18$ & 19 & & \\
\hline mouse & $79 / 25$ & 63 & 43 & $18 \%^{\mathrm{a}}$ \\
\hline rat & $39 / 8$ & 25 & 5 & $35 \%^{\mathrm{a}} \quad(16 \%)^{\mathrm{b}}$ \\
\hline $\operatorname{dog}$ & $28 / 7$ & 19 & 14 & $35 \%^{\mathrm{c}}(32 \%)^{\mathrm{b}}$ \\
\hline cyno & $36 / 2$ & 32 & 33 & $16 \%^{\mathrm{c}}$ \\
\hline
\end{tabular}

${ }^{\mathrm{a}}$ Solution in $20 \%(\mathrm{v} / \mathrm{v})$ Cremophor EL, $10 \%(\mathrm{v} / \mathrm{v})$ ethanol in water; ${ }^{\mathrm{b}} \mathrm{Suspension}$ of crystalline freebase in $0.5 \%(\mathrm{w} / \mathrm{v})$ methylcellulose, $0.2 \%(\mathrm{w} / \mathrm{v})$ polysorbate 80 in water; ${ }^{\mathrm{c}}$ Solution in $60 \%$ polyethylene glycol 400 in water 
There was little confidence in our human clearance predictions for GDC-0834 since there appeared to be species differences in the metabolic route of elimination with GDC-0834 being metabolized primarily by non-CYP mediated pathways. At the time, there was considerably less known about the in vitro to in vivo correlation of non-CYP mediated metabolism compared to CYP metabolism. ${ }^{24}$ Some reassurance was gained when $\mathbf{2}$ was studied in PXB chimeric mice with humanized livers and low clearance was observed. ${ }^{24}$ Due to the risks associated with the projected human PK of this molecule, we chose to file a single dose investigational new drug (IND) application. ${ }^{32}$ A single dose IND allowed us to expedite the understanding of the disposition of GDC-0834 (2) in human while reducing initial risk and cost. Furthermore, these human data would serve to inform the backup program.

Under the single dose IND, healthy volunteers received GDC0834 (2) orally (35 mg or $105 \mathrm{mg}$ ) and plasma concentrations were monitored. Parent compound $\mathbf{2}$ was not observed in plasma, rather only the product of amide hydrolysis M1 (Figure 5) and, in turn, its metabolites were detected. We later learned, perhaps surprisingly, that aldehyde oxidase (AO) and/or carboxy esterase, is the enzyme most likely responsible for the amide cleavage. $^{33} \mathrm{AO}$ is known to have higher expression in human as compared to dog, rat, mouse and cyno. In light of this, we focused our subsequent efforts on addressing this metabolic pathway with the goal of identifying a compound predicted to have improved metabolic stability in human.

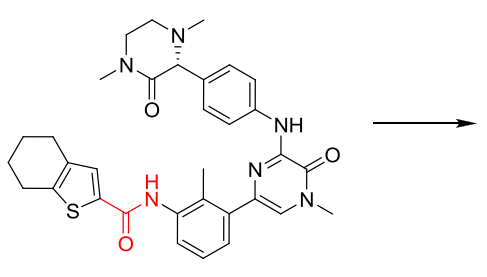

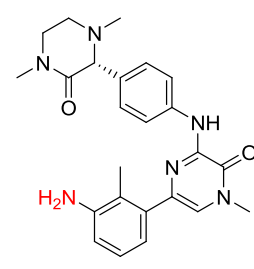

M1
Figure 5 Cleavage of $\mathbf{2}$ in human to generate aniline metabolite M2

In conclusion, GDC-0834, a highly potent and selective Btk inhibitor with acceptable preclinical in vivo profile was identified as the first clinical candidate from this series. Due to the large range of human in vivo predictions based on varying metabolism in preclinical species, we chose to take GDC-0834 into a single dose phase 1 healthy volunteer trial to rapidly learn the human PK profile and to inform potential back-up efforts. In human, 2, was found to be highly labile at the amide bond linking the H3moeity to the aniline ring, with this being a particular liability in human. Subsequent efforts have shown that this metabolic liability can be minimized by substitution of the aniline ring, through steric blockage of amide hydrolysis or cyclization of the amide - $\mathrm{NH}$ onto the $\mathrm{H} 3$-group. Our efforts in these areas will be described in upcoming communications.

\section{Acknowledgments}

We thank the Btk team members at Gilead (formerly CGI Pharmaceuticals Inc.), Genentech, Chem Partners, and AMRI for their contributions in generating the data for this manuscript. Use of the Advanced Light Source is supported by the U.S. Department of Energy under Contract No. DE-AC02$05 \mathrm{CH} 11231$

\section{References and notes}

1. Satterthwaite, A. B. Witte, O. N. Immunol. Rev. 2000, 175, 120.

2. Brunne, R. C.; Mue $\square$ ller, B.; Wirth, T. Histol. Histopathol. 2005, 20, 945.

3. Di Paolo, J. A.; Huang, T.; Balazs, M.; Barbosa, J.; Barck, K. H.; Bravo, B. J.; Carano, R. A.; Darrow, J.; Davies, D. R.; DeForge, L. E.; Diehl, L.; Ferrando, R.; Gallion, S. L.; Giannetti, A. M.; Gribling, P.; Hurez, V.; Hymowitz, S. G.; Jones, R.; Kropf, J. E.; Lee, W. P.; Maciejewski, P. M.; Mitchell, S. A.; Rong, H.; Staker, B. L.; Whitney, J. A.; Yeh, S.; Young, W. B.; Yu, C.; Zhang, J.; Reif, K.; Currie, K. Nat. Chem. Biol. 2011, 7, 41.

4. Puri, K. D., Di Paolo, J.; Gold, M. R. Int. Rev. Immunol. 2013, 32, 397.

5. Uckun FM, Qazi S. Expert Opin Ther Pat. 2010, 20, 1457.

6. Smith, C. I. E.; Islam, K.B.; Vorechovsky, I.; Olerup, O.; Wallin, E.; Rabbani, H.; Baskin, B.; Hammarstrom, L. Immunol. Rev. 1994, 138, 159

7. Bruton, O. C. Pediatrics 1952, 9, 722

8. Howard, V.; Greene, J.M.; Pahwa, S.; Winkelstein, J. A.; Boyle, J. M.; Kocak, M.; Conley, M. E. Clin. Immunol.. 2006, 118, 201.

9. Satterthwaite, A.B.; Witte, O.N. Immunol. Rev. 2000, 175, 120.

10. Tsukada, S., Rawlings, D.J.; Witte, O.N. 1994 Curr. Opin. Immunol. 6 , 623

11. Steinberg, D. D. J. Clinic. Invest. 1982, 70, 587.

12. Jansson, L.; Holmdahl, R. Clin. Exp. Immunol. 1993, 94, 459.

13. Lou, Y.; Owens, T. D.; Kuglstatter, A.; Kondru, R. K.; Goldstein, D. M J. Med. Chem. 2012, 55, 4539 .

14. Pan, Z. Drug News Perspect. 2008, 21, 357.

15. Rokosz, L. L.; Beasley, J. R.; Carroll, C. D.; Lin, T.; Zhao, J.; Appell, K. C.; Webb, M. L. Expert Opin. Ther. Targets 2008, 12, 883.

16. Uckun, F. M.; Tibbles, H. E.; Vassilev, A. O. Med. Chem. 2007, 7, 624

17. Chavez, J. C.; Sahakian, E.; Pinilla-Ibarz, J. Core Evidence, 2013, 8, 37

18. Akinleye, A.; Chen, Y. I.; Mukhi, N.; Song, Y.; Liu, D. JJ. Hematol. Oncol. 2013, 6, 59.

19. http://www.fda.gov/Drugs/InformationOnDrugs/ApprovedDrugs/ucm37 4857.htm

20. http://www.clinicaltrial.gov/ct2/results?term=ibrutinib\&Search=Search

21. http://clinicaltrials.gov/show/NCT01975610

22. Brittelli, D. R. et al. WO/2006/099075 2006

23. Currie, K. S. Brussels, Belgium; 2010 EFMC 21st International Symposium on Medicinal Chemistry, Brussels, Belgium

24. Liu, L.; Halladay, J.; Shin, Y.; Wong, S.; Coraggio, M.; La, H.; Baumgardner, M.; Le, H.; Gopaul, S.; Boggs, J.; Kuebler, P.; Davis, J.; Liao, C.; Lubach, J.; Deese, A.; Sowell, G.; Currie, K.; Young, W.; Khojasteh, C.; Hop, C.; Wong, H. Drug Metab. Dispos., 2011, 39, 1840-9.

25. Kalgutkar; A. S; Gardner, I; Obach, R. S.; Shaffer, C. L.; Callegari, E.; Henne, K. R.; Mutlib, A. E.; Dalvie, D. K.; Lee, J. S.; Nakai, Y; O'Donnell, J. P.; Boer. J.; Harriman, S. P. Curr Drug Metab. 2005, 3 , 161 .

26. Rademacher, P. M.; Woods, C. M.; Huang, Q.; Szklarz, G. D.; Nelson, S. D. Chem. Res. in Toxicol., 2012, 25, 895.

27. Recent example: Invokana ${ }^{\mathrm{TM}}$ (canaglifozia) http://www.invokanahcp.com/prescribing-information.pdf

28. Liu, L.; Di Paolo, J.; Barbosa, J.; Rong, H.; Reif, K.; Wong, H. J. Pharmacol. Exp. Ther. 2011, 338, 154

29. Muckelbauer, J.; Sack, J. S.; Ahmed, N.; Burke, B.; Chang, C. Y.; Gao, M.; Tino, J.; Xie, D.; Tebben, A. Chem Biol. Drug Des. 2011, 78, 793.

30. See the Supplementary data for the experimental details associated with the co-crystal structure of BTK with GDC-834. The coordinates and structure factors have been deposited with the protein data bank and assigned the accession code $4 \mathrm{OTF}$

31. Blomgren, P.A. et.al. U.S. Patent 7,8884,108.

32. http://www.fda.gov/downloads/Drugs/GuidanceComplianceRegulatoryI nformation/Guidances/ucm078933.pdf

33. Sodhi, J.; Wong, S.; Liu, L.; Khojasteh, S. C.; Hop, C. E. C. A; Barr, J. T.; Jones, J. P.; Kirkpatrick D. S.; Halladay, J. Drug Metab. Dispos., submitted. 


\section{Graphical Abstract}

Potent and Selective Bruton's Tyrosine Kinase

Leave this area blank for abstract info. Inhibitors: Discovery of GDC-0834

Wendy B. Young, James Barbosa, Peter Blomgren, Meire C. Bremer, James J. Crawford, Donna Dambach, Steve Gallion, Sarah Hymowitz, Jeffrey E. Kropf, Seung H. Lee, Lichuan Liu, Joe Lubach, Jen Macaluso, Pat Maciejewski, Brigitte Maurer, Scott A. Mitchell, Daniel F. Ortwine, Julie Di Paolo, Karin Reif, Heleen Scheerens, Aaron Schmitt, C. Gregory

Sowell, Xiaojing Wang, Harvey Wong, Jin-Ming Xiong, Jianjun Xu, Zhongdong Zhao and Kevin S. Currie

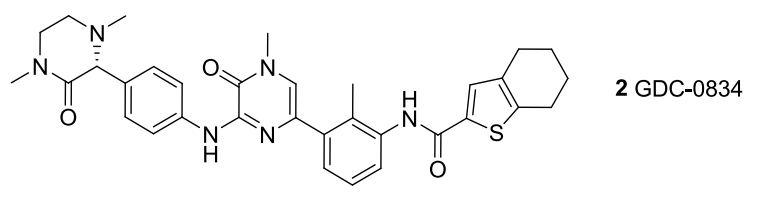

